\title{
Problems of legal regulation of grant support for fundamental research in the Russian Federation
}

\author{
Ekaterina Sapozhnikova, Elena Sivolapenko* \\ Don State Technical University, 344000 Rostov-on-Don, Russian Federation
}

\begin{abstract}
The development of science-intensive industry and the availability of a system to support scientific activities today occupy a key place in the policy of any strong and independent state. In recent years, grants have become a priority in the formation of sources of funding for research and innovation in various fields. In accordance with the strategy of innovative development for the period up to 2020 the procedure of improvement of the legislation of the Russian Federation providing legal regulation of grant support of scientific activity is carried out in Russia. However, the process of improving Russian legislation in the field of research funding has not yet been completed. The main problems today are the uncertainty of the legal regime of the grant in the Russian legislation, the lack of a clear mechanism governing the relationship of grant-givers, grantees and procedures for the provision of scientific grants, as well as the imperfection of tax legislation on the taxation of grants.
\end{abstract}

\section{Introduction}

One of the main tasks of any developed state is to create conditions for the effective development of science and technology. Science is one of the fundamental spheres of state activity, which is a tool for entering the global market of division of labor.

The issue of research funding occupies an important place in any state, one of the latest global trends has been the rapid development of the system of grant funding for research, which was the reason for the establishment of the Institute of grant support in the Russian Federation.

According to leading researchers-economists, the history of grants as an independent source of funding for science began in the XVII century, when the largest scientific communities began to use peer review to evaluate scientific papers describing the experiments. The first mentions of grants relate to the history of great Britain was in 1960, then that the Royal society of London began to allocate funds to scientists for research. In Europe research grants were introduced by the Frenchman R. Bonaparte in 1907. However, the main elements of the formal organization of scientific funds and grant support system

\footnotetext{
* Corresponding author: vladimirovnale95@mail.ru
} 
were formed in the United States in the early XX century. At that time, it was the development of the tax and antitrust laws of the United States that prepared everything for the institutionalization of relations in the field of gratuitous support for scientific research. Grant support for science of the United States was implemented to a greater extent not only by state funds, but through private funds. Such private foundations as Carnegie Institute of science (1902), Russell Sage Foundation (1907), Rockefeller Foundation (1913), Ford Foundation (1936) were created. It was in the Carnegie Corporation and the Rockefeller Foundation that the concept of a grant as a special gratuitous contract was first introduced, imposing an obligation on the grantee to perform certain work and transfer its results to public use in the form of a publication.

NSF and NIH (USA) and NSERC (Canada) are among the leading organizations in the world that provide grant support for basic science at present, in Western Europe - DFG (Germany), CNRS (France), ERC and ESF (EU), and in East Asia-JSPS (Japan)and NRF (South Korea).

The system of financing of fundamental science in Russia does not have a rich history, as it appeared only in the 90s of the XX century. The term "grant" became famous in Russia in connection with the activities of the open society Institute (1993) - an international charitable organization founded by financier and philanthropist George Soros. It contributed more than \$ 130 million between 1993 and 1996 for the development of Russian science. With the money allocated, the laboratories purchased equipment and reagents, and about 120 Russian scientific libraries replenished their funds. Finally, scientists were paid to travel to scientific conferences around the world - and this was also extremely important for those who were just learning to interact with the global scientific community.

\section{Results and discussion}

Nowadays the Russian legal system has certain shortcomings in terms of state regulation of scientific activity. Work on improvement of the legislation in this area which began with adoption of the Federal law of 23.08.1996 N 127-FL "about science and the state scientific and technical policy" proceeds. A special place in this regard is occupied by the issues of budget financing of science, in particular, the status of grant-givers, grantees and the procedure for granting scientific grants.

Federal law of 23.08.1996 N 127-FL (ed. from 26.07.2019) "On science and state scientific and technical policy" for the first time in the Russian legislation gives the definition of the grant and relate to this notion of money and other means, transferred gratuitously and irrevocably by citizens and legal entities, including foreign citizens and foreign legal entities and international organizations entitled to grants on the territory of the Russian Federation established by the Government of the Russian Federation on the implementation of specific scientific technical programs and projects, innovative projects, carrying out specific research on the terms provided by the grant makers [1].

The definition of a grant is also enshrined in the Tax legislation of the Russian Federation. According to art. 251 (income not taken into account in determining the tax base) of the Tax code of the Russian Federation grants are recognized as cash or other property if their transfer (receipt) meets the following conditions: grants are provided on a gratuitous and irrevocable basis by Russian individuals, non-profit organizations, as well as foreign and international organizations and associations on the list of such organizations approved by the Government of the Russian Federation for the implementation of specific programs in the field of education, art, culture, science and sports (except professional sports), health, environmental protection, protection of the rights and freedoms of man and citizen provided by the legislation of the Russian Federation, social service of the poor and socially unprotected categories of citizens, and in the case of grants of the President of the Russian Federation for 
implementation of activities (programs, projects), certain acts of the President of the Russian Federation; grants are provided on the terms determined by the grant-giver, with the mandatory provision of a report to the grant-giver on the intended use of the grant [2].

Article 78 of the Budget Code of the Russian Federation also contains mention of grants in the form of subsidies, including those provided on a competitive basis in the areas of budgetary allocations for the provision in accordance with the decisions of the President of the Russian Federation, the Government of the Russian Federation, the higher official of the subject of the Russian Federation, Supreme Executive body of state power of a subject of the Russian Federation, local administration, legal entities (except for state (municipal) institutions), individual entrepreneurs, individuals [3].

In the Russian civil legislation, the concept of a grant as a type of transaction is absent. In practice, the contract governing the grant is not fully covered by any of the types of obligations provided for by the civil code of the Russian Federation. The text of the Civil code of the Russian Federation does not contain any mention of the grant. There is also no special regulation of the civil law type of contract for the grant. From the point of view of civil law regulation, a grant within the meaning of Chapter 32 of the Civil code of the Russian Federation is qualified as a donation. It should be noted that such qualification appeared in judicial acts when considering disputes over payments made at the expense of grants [4].

According to article 582 of the civil code (as amended by the Federal law of 28.03.2017 $\mathrm{N} 39-\mathrm{FL}$ ), a donation is a gift of a thing or right for generally useful purposes. Donations may be made to citizens, medical, educational organizations, social service organizations and other similar organizations, charitable and scientific organizations, foundations, museums and other cultural institutions, public and religious organizations, other non-profit organizations in accordance with the law, as well as to the state and other subjects of civil law. No permission or consent is required to accept a donation.

On the basis of the above legislative definitions of the concept of grant, we see that a significant legal problem in the implementation of the system of grant financing of fundamental scientific research is the uncertainty of the legal regime of the grant in the Russian legislation. The legal status of grants is differently qualified by various branches of legislation, such as legislation in the field of education and science, tax, civil and budgetary legislation, which greatly complicates the development of the grant system for financing scientific activities of the state.

Special attention in the framework of our study deserves the issue of taxation of grants. Consider the calculation of corporate income tax, VAT, personal income tax and insurance premiums for grants.

The interpretation of subparagraph 14 of paragraph 1 of article 251 of the tax code is important in the taxation of grants with income tax.

There are several conditions under which "grant" can be classified as an object of taxation for Chapter 25 of the tax code «corporate income Tax»:

1) grants are provided on a gratuitous and irrevocable basis;

2) provided by Russian individuals, non-profit organizations, as well as (according to the approved list) foreign and international organizations and associations;

3 ) are provided for the implementation of specific programs in the field of education, art, culture, science, physical culture and sports (except for professional sports), health protection, environmental protection, protection of human and civil rights and freedoms, social services for the poor and socially vulnerable categories of citizens;

4) are provided on the terms determined by the grant-giver, with the mandatory provision of a report to the grant-giver on the intended use of the grant.

Subject to certain conditions, grant amounts are not taken into account in determining the tax base for corporate income tax (letter no. of the tax and customs policy Department of the 
Ministry of Finance of 18 September 2018). 03-03-06/3/66790). The following conditions must be met at the same time:

- grants are issued on the terms of the grant maker. At the same time, he must be provided with a report on the intended use of the grant;

- grants are paid on a gratuitous and irrevocable basis by Russian individuals, NGOs, foreign and international organizations and associations on the list of such organizations, which is approved by the Government of the Russian Federation. It can be Russian and foreign organizations $[5,6]$. At the same time, specific programs in the field of art, science, education, culture, physical culture and sports (except for professional sports), environmental protection, health protection, protection of human and civil rights and freedoms provided for by the legislation of the Russian Federation can be implemented at the expense of the grant. As well as social service programs for the poor and socially vulnerable categories of citizens (podp. 14 item 1 of Art. 251 of the Tax code);

- taxpayers who received funds of target financing are obliged to keep separate accounting of the income (expenses) received (made) as target financing (PP. 14 p. 1 article 251, p. 2 article 251 of the tax code). At the end of the tax period, the institution that received the grant shall submit to the tax authorities a report on the intended use of the funds received as part of the income tax return. In the absence of separate accounting, these funds are considered as taxable from the date of their receipt.

At least one of the above conditions is not found, the amount of grants should be taken into account when determining the tax base for corporate income tax.

If the funds received under the grant are used for other purposes, as well as in the absence of separate accounting of funds of target financing, then there is a taxable non-operating income. According to item 14 of Art. 251 of the tax code of the Russian Federation target means are subject to inclusion in structure of the non-operating income if the recipient did not use them on purpose within one year after the end of the tax period in which they arrived. However, the grant-givers financing projects at the expense of budgetary funds always provide in contracts return of the unspent sums as permission to use the balance of the grant for the purposes which are not connected with the financed project contradicts the principle of efficiency of expenditure of budgetary funds.

Moreover the government of the Russian Federation, the President of the Russian Federation, Federal ministries and agencies are not named in the composition of grant-givers whose grants are not subject to income tax. However, if a grant from these sources is received by an institution, it is not subject to income tax on another basis - as property received by state and municipal institutions by decision of Executive authorities at all levels (PP. 8 clause 1 of article 251 of NK of the Russian Federation).

If the institution performs work on the project as a contractor, and the financing of the work is carried out by another organization-grantee at the expense of grants, such work is subject to income tax.

Grants in foreign currency have their own peculiarities of tax accounting. Grant amounts in foreign currency are translated into rubles at the official exchange rate of the CBR on the date of income recognition (clause 3 of article 248 of the tax code). In the result, there may be exchange rate difference (positive, negative) (paragraph 11 of article 250 and PP. 5 p. 1 Art. 265 of the tax code). Foreign exchange gains are non-operating income and are subject to corporate income tax.

As for the calculation of value added tax when using grants, as a General rule, it is not necessary to charge VAT on the amounts received within the framework of targeted financing. This is due to the fact that the object of VAT is the sale of goods, works and services. In this case, the implementation does not occur - the source of funding (investor) only compensates the recipient of the amount spent on targeted activities. This conclusion is made by subparagraph 1 of paragraph 1 of article 146 and article 39 of the Tax code. 
Let us turn to the question of taxation grants a tax to incomes of physical persons. Physical persons can receive income through grants in two cases:

- if they are directly grantees;

- if they are employees of the institution-grantee and participants of the project financed by the grant.

When determining the tax base for personal income tax, all income of the taxpayer in cash or in kind is taken into account (article 210 of the tax code).

The amounts received by taxpayers in the form of grants (gratuitous assistance) provided to support science and education, culture and art in the Russian Federation by international, foreign and (or) Russian organizations according to the lists of such organizations approved by the Government of the Russian Federation (clause 6 of article 217 of the tax code) are exempt from personal income tax.

The situation with taxation is much more complicated if the grant is received by the institution, and its employees receive remuneration from the grant funds. In letters of UFNS of Russia across Moscow of 19.01.2010 N 20-15/3/003707@, from 24.12.2009 N 2015/3/136430@it is explained that the benefit provided for by paragraph 6 of article 217 of the tax code applies only to grants provided by organizations that are grant-givers directly to taxpayers-individuals. Therefore, the effect of this benefit on the amount of grants received by a legal entity does not apply. A legal entity, being a recipient of targeted funds in the form of a grant from the RFBR, is obliged to calculate, withhold and pay the amount of personal income tax from payments made to individuals from the grant funds.

The issue of accrual of insurance premiums for payments to individuals at the expense of the grant is explained in the letters of the Ministry of Finance of Russia [7]. According to the Ministry of Finance, if the organization makes payments to individuals who are with her in labor relations or concluded civil-law contracts on performance of works, rendering of services payments (regardless of their source of funding, including through grants) are subject to insurance premiums. With the exception of the payments listed in article 422 of the tax code.

Russian legislation has not always had time to adapt to international requirements. In the mid-90s of the XX century there was a situation when in order to comply with the international rules of financing of science and education, it was necessary to adopt an addition to the tax legislation, which has a retroactive effect. Grants from the Soros Foundation allocated and distributed among Russian scientists and teachers became subject to taxation under the Russian legislation in force at the time. There was a conflict of national and international law. According to international standards, charitable grants in the field of education and science are not taxed. Tax exemption is one of the necessary conditions under which the activities of the organization providing these grants in the territory of another state, is considered charitable. If the grants are taxed, the non - resident organization loses its special status as a charitable organization and is obliged to pay all other taxes from which it was exempted at the place of registration. It was possible to correct the mistake by adopting a special addition to the VAT law concerning international and foreign grants. The norm adopted in 1995 was retroactive and regulated legal relations that had occurred long before the adoption of the norm.

The legislator has repeatedly made attempts to clarify and specify the rules for the use of grants, but these clarifications have not always contributed to the development of the grant system of financing science of the state. Due to the erroneous position of the legislator in 2000, the Ministry of Finance of the Russian Federation received regulatory grounds not to classify scientific grants as subventions and subsidies, which is why the activities of the Russian Foundation for basic research and the Russian humanitarian science Foundation for grants were practically suspended. 


\section{Conclusions}

On the basis of the conducted research of problems of legal regulation of grant support of fundamental scientific researches, it is possible to come to the following conclusions. The Russian legislation regulating the system of grant support for scientific research has a number of imperfections and requires improvement in terms of defining the legal regime of the grant and creating a clear mechanism for interaction of all participants in grant relations, determining their rights and obligations. Also, the Russian grant system, formed relatively recently, is now forced to fill the gaps formed by insufficient budget funding of scientific organizations in the past, but the main approach of grant funding should be to support unscheduled, proactive research in priority areas of science, as well as to create new organizations and teams focused on the practical implementation of the latest scientific achievements.

It should be noted that the legislator is constantly taking measures to improve the legislative regulation of the grant system, but today there are still many questions. So, one of the main directions of strategy of innovative development for the period till 2020 (approved by the order of the Government of the Russian Federation of December 8, 2011 2227-R) in Russia, it is planned to expand and develop the grant form of funding for research with a simultaneous gradual reduction in the share of funding in the form of government contracts for research in the field of fundamental science. At the same time, the increase in funding for basic science is planned to be achieved by increasing the amount of funding for research within the Russian Foundation for basic research (RFBR) and the Russian humanitarian science Foundation, the program of basic research of the state academies of Sciences, formed on a competitive basis, as well as research conducted in universities. The legislator also plans to improve the mechanisms for implementing the system of grant funding for science and pay special attention to the development of international cooperation on grant support for fundamental scientific research.

\section{References}

1. Federal law of 23.08.1996 N 127-FL (ed. of 26.07.2019)"on science and state scientific and technical policy".

2. "The tax code of the Russian Federation (part two)" of 05.08.2000 N 117-FL (edition of 30.07.2019)

3. "The civil code of the Russian Federation (part two)" of 26.01.1996 N 14-FL (edition of 29.07.2018, with change. from 03.07.2019) (with change. and extra, Intro. effective from 30.12.2018)

4. The resolution of the RF Government of 15 July 2009 N 602 "About approval of the list of Russian organizations that received taxpayer grants (gratuitous aid) which is provided to support science, education, culture and arts in the Russian Federation, are not subject to taxation»»

5. The list of international and foreign organizations received by taxpayers grants (gratuitous assistance) which are not subject to taxation and are not considered for tax purposes in the income of Russian organizations - recipients of grants (approved. by the order of the Government of the Russian Federation of June 28, 2008 N 485)

6. Letters from the Ministry of Finance 27.11.2018 № 03-15-06/85479, 02.11.2018 № 03-15-05/79163 